\title{
Influence of Palm Oil-Based Polyol on the Properties of Flexible Polyurethane Foams
}

\author{
Henryk Pawlik • Aleksander Prociak
}

Published online: 24 November 2011

(C) The Author(s) 2011. This article is published with open access at Springerlink.com

\begin{abstract}
This paper describes the effect of the modification of polyurethane system with palm oil-based polyol on the cell structure and physical-mechanical properties of polyurethane foams. Flexible polyurethane foams were prepared by substituting a part of petrochemical polyether-polyol with the palm oil polyol. Selected physical-mechanical properties of these foams were examined and compared to the properties of reference foam. The properties such as apparent density, tensile strength, elongation at break, resilience, compressive stress and thermal stability were analyzed. It was found that the modifications of polyurethane formulation with palm oil polyol allow to improve selected properties of final products.
\end{abstract}

Keywords Renewable raw materials · Palm oil-based polyol P Polyurethane flexible foams $\cdot$ Physical-mechanical properties

\section{Introduction}

Polyurethanes (PUR) are one of the most versatile polymeric materials. They can be used as foams, elastomers, coatings, adhesives and sealants due to the wide range of their properties. Flexible and rigid foams have the largest market of PUR products [1].

H. Pawlik · A. Prociak $(\square)$

Department of Chemistry and Technology of Polymers,

Cracow University of Technology, ul. Warszawska 24,

31-155 Kraków, Poland

e-mail: aprociak@pk.edu.pl
All PUR products relies on petroleum oil as the feedstock for their major raw materials: polyols and isocyanates. The rising prices of petrochemical raw materials and decreasing deposits of petroleum resources cause the increasing of the interest in the applications of biodegradable and renewable polymeric materials [2].

Developing bio-renewable feedstock from vegetable oils for PUR manufacturing becomes highly desirable for both economic and environmental reasons. The derivatives of vegetable oils exhibit capacity for biological degradation [3]. Moreover, life cycle assessment of vegetable oil polyols shows environmental benefits like reduction in the demand of fossil resources and formation of very low greenhouse gas emission [4]. Therefore, the hydroxylated derivatives of vegetable oils are interesting and alternative replacements for petrochemical polyols in the synthesis of PUR materials [5-9].

Hydroxyl groups in polyol components are required in order to react with isocyanate and to form urethane bonds. Most of vegetable oils do not contains hydroxyl groups. Prior to their use for polyurethanes preparation they must be converted into a polyol by chemical modification.

Nowadays, several methods for conversion of vegetable oils into polyols are known. All of them are based on chemical modification of ester groups or double bonds in unsaturated chains of fatty acids. The most common conversion methods are direct oxidation [10], ozonolysis [11], epoxidation followed by ring opening [12], hydroformylation [13], and transesterification [14]. Each of them has advantages and disadvantages [8]. Various types of vegetable oils differ in the composition of saturated and unsaturated fatty acids [15]. The diversity in unsaturation degree allows the synthesis of oil polyols with variable hydroxyl number [8]. 
Polyols applied in flexible foams should have low hydroxyl values (generally $\mathrm{LOH}<100 \mathrm{mg} \mathrm{KOH} / \mathrm{g}$ ) and/ or high molecular weights (generally $\mathrm{M}_{\mathrm{n}}$ between 3,000 and $6,000 \mathrm{~g} / \mathrm{mol}$ ) to decrease cross-linking density and to improve elasticity of final products. Palm oil is a readily available renewable agricultural raw material, which can be used for the synthesis of polyols suitable for the preparation of flexible or semi-rigid PUR foams [16, 17]. Analysis of the content of unsaturated bonds in various oils confirmed that palm oil is a convenient raw material for the synthesis of the polyols with low and medium content of hydroxyl groups [16]. Low content of unsaturated bonds $(\mathrm{LI}=50-55)$ in palm oils allows to obtain (using the epoxidation method followed by ring opening) the products with hydroxyl numbers lower than $200 \mathrm{mg}$ $\mathrm{KOH} / \mathrm{g}$ and very low content of unreacted double bonds [7]. Additionally, palm oil is the cheapest among the ones currently produced vegetable oils and had the largest contribution of the total production in 2010. Palm and palm kernel oils production was recorded at 53.6 million tonnes, which represents ca. $37 \%$ of the global vegetable oil market [18].

Palm oil-based polyols can be synthesized using different methods. The examples of palm oil applications in the synthesis of polyols for the preparation of rigid polyurethane foams can be found in literature. Such polyols are usually obtained by transesterification with the use of various agents such as diethanolamine (DEA) $[19,20]$.

The polyol from palm oil can be obtained also using the method, which involves the epoxidation of double bonds followed by oxirane ring opening by various agents. In the last few years, several works have been aimed at the use of such polyols for the preparation of flexible foams [21, 22]. These polyols have a hydroxyl number in the range $70-130 \mathrm{mg} \mathrm{KOH} / \mathrm{g} \mathrm{[23].} \mathrm{Using} \mathrm{the}$ glycols in the second step of this method it is possible to obtain palm oil-based polyols with primary and secondary hydroxyl groups. Another advantage of this method is the use of whole molecules of triglycerides in the preparation of polyol, thereby the resulting products are characterized by a high content of renewable raw materials. The content of hydroxyl groups in the oil polyols can be designed by choosing appropriate conditions of the epoxidation reaction [16]. The application of different alcohols as ring-opening agents and chain extenders allows affecting the content of soft segments in PUR foams [24].

In this work, flexible foams were prepared by replacing up to $15 \%$ of conventional petrochemical polyether polyol with palm oil polyol. The influence of such modification on the selected physical-mechanical properties of final products is discussed.

\section{Experimental}

\section{Raw Materials}

- palm oil-based polyol prepared on laboratory scale in Cracow University of Technology

- Rokopol G-1000, polyether polyol (PCC Rokita S.A.)

- Alfapol M-111, polyether polyol (ALFA Systems Sp. z o.o. Brzeg Dolny)

- Alfapol T-501, polyester polyol (ALFA Systems Sp. z o.o. Brzeg Dolny)

- TDI, toluene diisocyanate (80:20 wt\% mixture of 2,4and 2,6-isomers, ZACHEM S.A.)

- DABCO T-9, tin catalyst (Air Products and Chemicals, Inc.)

- DMCHA, amine catalyst (Texaco Chemical Deutschland, $\mathrm{GmbH}$ )

- DABCO BL-11, amine catalyst (Air Products and Chemicals, Inc.)

- Niax Silicone L-627, surfactant (Momentive Performance Materials)

- distilled water

Three commercially available petrochemical polyols: Alfapol M-111, T-501 and Rokopol G-1000 were selected for the preparation of reference flexible foams. These polyols were chosen in order to obtain flexible polyurethane foams (PURFs) with low resilience properties.

Palm oil-based polyol used in this study was prepared in two-step process. Firstly, the unsaturated bonds of triglycerides were epoxidized using hydrogen peroxide as an oxidizing agent and then hexamethylene glycol was applied to open oxirane rings. Laboratory synthesis of palm oil polyol was carried out similarly as described in previous published work [16]. The molecular weight of palm oil polyol used in this study was determined by gel permeation chromatography at room temperature with using PS standards (Watters). Number average molecular weight (Mn) and molecular weight polydispersity $(\mathrm{Pd})$ were affected by the conversion of oxirane groups into hydroxyl groups and oligomerisation degree. In Fig. 1 multimodal GPC character is shown. There are two major fractions in the GPC chromatogram of the palm oil polyol. The dominant peak corresponds to the hydroxyl derivative of triglyceride with average functionality of ca. 2.5. The second broad peak in GPC (minor peak) corresponds to dimers and trimers and is related to both with variations in fatty acid substituent and oligomerization of a small fraction of palm oil polyol during the modification. The characteristics of used polyols are shown in Table 1.

Toluene diisocyanate (TDI) with NCO content $46 \mathrm{wt} \%$ was used as the isocyanate component for the preparation of PUR system. Water was applied as a chemical blowing 


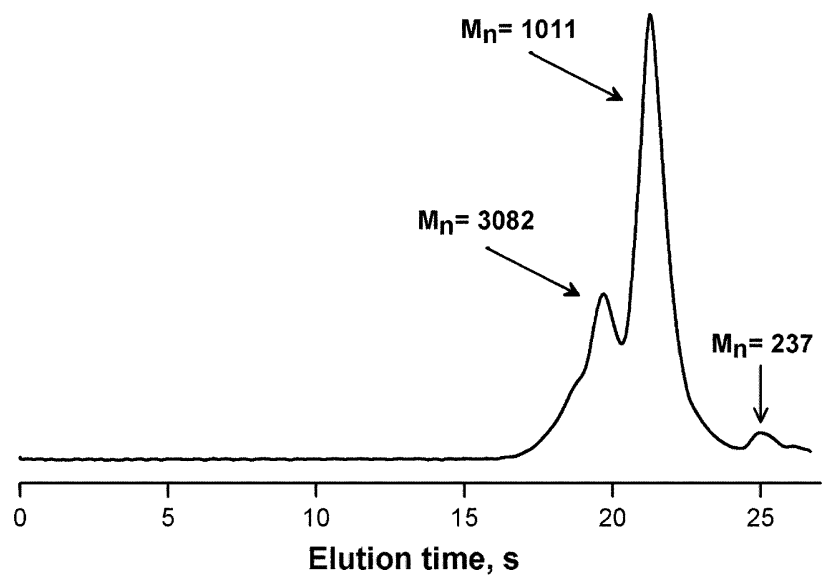

Fig. 1 GPC chromatogram of palm oil polyol

agent. Gelling (DABCO T-9, DMCHA) and blowing (DABCO BL-11) catalysts and silicone-based surfactant (Niax Silicone L-627) were added to formulation in order to prepare foams with an open cellular structure.

\section{Foam Preparation}

PURFs were prepared on laboratory scale in one step synthesis by mixing A and B components. Firstly, the palm oil polyol was mixed with petrochemical polyols, catalysts, water and surfactant (component A). TDI as a component $\mathrm{B}$ was added to component $\mathrm{A}$ and the mixture was stirred for $10 \mathrm{~s}$ with an overhead stirrer at 2,000 rpm. Then, the prepared mixture was poured into the open mould $(14 \times 12 \times 7 \mathrm{~cm})$. The foams rise freely in vertical direction. After finishing the free rise, each polyurethane foam was placed in an oven preheated to $110{ }^{\circ} \mathrm{C}$ for $5 \mathrm{~min}$ in order to make possible the proper curing. Reference foams were prepared using only petrochemical polyols. PUR systems were modified by replacing petrochemical polyether polyol in premixes with 5,10 , and $15 \mathrm{wt} \%$ of palm oil polyol. Only polyol G 1000 , which has the average molecular weight and functionality similar to palm oil polyol has been replaced. The formulations used for preparation of the foam samples are shown in Table 2. The amount of each additive was calculated on 100 parts by
Table 2 Flexible polyurethane foams formulations

\begin{tabular}{lcrrr}
\hline Component, g & \multicolumn{4}{l}{ Foam symbol } \\
\cline { 2 - 5 } & \multicolumn{1}{l}{ REF } & \multicolumn{1}{c}{ P05 } & \multicolumn{1}{c}{ P10 } & \multicolumn{1}{c}{ P15 } \\
\hline M-111, T 501, G1000 & 100.00 & 95.00 & 90.00 & 85.00 \\
PP-HEX & - & 5.00 & 10.00 & 15.00 \\
DMCHA & 0.12 & 0.12 & 0.12 & 0.12 \\
T-9 & 0.40 & 0.40 & 0.40 & 0.40 \\
BL-11 & 0.06 & 0.06 & 0.06 & 0.06 \\
L-627 & 1.40 & 1.40 & 1.40 & 1.40 \\
Water & 3.20 & 3.19 & 3.19 & 3.18 \\
TDI & 34.40 & 34.10 & 33.80 & 33.40 \\
\hline
\end{tabular}

weight of total polyol components. The isocyanate index was 0.7 .

The prepared foams were conditioned at $22{ }^{\circ} \mathrm{C}$ and $50 \%$ relative humidity for $24 \mathrm{~h}$. After that they were cut to specimens for testing of physical and mechanical properties.

\section{Foams Characterization}

Selected physical-mechanical properties of PURFs were measured according to the appropriate standards; the apparent density PN-EN ISO 845:2000; the compression value at $40 \%$ strain $\left(\mathrm{CV}_{40}\right)$ PN-EN ISO 3386-1:2000, tensile strength and elongation at break PN-EN ISO 1798:2001. The cellular structure images of PURFs were taken using an optical microscope with a video track (PZO Warszawa). Foam slices were cut after freezing the foam samples in liquid nitrogen. Aphelion ${ }^{\mathrm{TM}}$ software was applied to analyze the images of foam structures. Cell size (height and width) was determined, and then cross-section surface and cell anisotropy were calculated on the base of more than 300 cells. Anisotropy coefficient was calculated dividing the height by the width of the cell. The content of closed cells was determined according to PN-ISO 4590. Thermogravimetric analysis (TGA) was carried out by TG Netzsch thermogravimetric analyzer (TG 209) at the heating rate of $10{ }^{\circ} \mathrm{C} / \mathrm{min}$ in the air atmosphere from 20 to $600{ }^{\circ} \mathrm{C}$. The resilience of foams was investigated by ball rebound test according to PN-EN ISO 8307:2007. The test
Table 1 Characterization of polyols

\begin{tabular}{lllll}
\hline Properties & $\begin{array}{l}\text { Palm oil } \\
\text { polyol }\end{array}$ & $\begin{array}{l}\text { Rokopol } \\
\text { G1000 }\end{array}$ & $\begin{array}{l}\text { Alfapol } \\
\text { M-111 }\end{array}$ & $\begin{array}{l}\text { Alfapol } \\
\text { T 501 }\end{array}$ \\
\hline Number average molecular weight $\left(\mathrm{M}_{\mathrm{n}}\right), \mathrm{g} / \mathrm{mol}$ & 1,284 & $\sim 1,000$ & $\sim 6,000$ & $\sim 2,000$ \\
Functionality $\left(\mathrm{f}_{\mathrm{n}}\right)$ & 2.5 & 3 & 3 & 2 \\
Hydroxyl number, $\mathrm{mg} \mathrm{KOH} / \mathrm{g}$ & 110 & 160 & 27 & 54 \\
Water content, $\mathrm{wt} \%$ & 0.25 & 0.1 & 0.1 & 0.05 \\
Viscosity at $25{ }^{\circ} \mathrm{C}, \mathrm{mPa} \mathrm{s}$ & 1,468 & $200-300$ & 1,200 & 650 in $75^{\circ} \mathrm{C}$ \\
\hline
\end{tabular}


was carried out by dropping $3.18 \mathrm{~mm}$ diameter steel ball on a specimen from the fixed height $(0.5 \mathrm{~m})$ and determining the rebound height. Soft-segment (SS) glass transition temperatures were determined using dynamic mechanical analysis (TA Instruments-DMA Q800). Foam disks $12.5 \mathrm{~mm}$ (diameter) $\times 10 \mathrm{~mm}$ (thickness) were tested in sinusoidal oscillation mode between two parallel plates. Storage modulus (G') was recorded at the frequency of $1 \mathrm{~Hz}$ in the range of temperatures from -100 to $200{ }^{\circ} \mathrm{C}$. The temperature ramp rate was $3{ }^{\circ} \mathrm{C} / \mathrm{min}$.

\section{Results and Discussion}

The investigations were carried out to determine the influence of the different content of the palm oil polyol in PUR formulation on the mechanical properties of flexible foams. The attempts to replace the possibly large part of petrochemical polyol with the palm oil polyol without other changes the formulation were undertaken. Porous materials containing 5, 10, and $15 \mathrm{wt} \%$ of palm oil polyol in the polyol premix (component A) were successfully obtained. In the case of foams, that contained palm oilbased polyol in an amount exceeding $15 \mathrm{wt} \%$ shrinkage effects were observed. Therefore, those materials were not evaluated. It was found that significant changes in the foam formulation are required in order to obtain foams with higher content of palm oil polyol. Making changes in such foam formulation is necessary due to different structure and nature of palm oil-based and petrochemical polyols. In order to eliminate unfavorable effects as shrinkage the correction of the foam formulation, including quantities of used catalysts and surfactants, have to be made, however, such modification excludes the direct comparison of such materials.

The results showed that apparent density of all modified foams was slightly higher (less than $8 \%$ ) than in the case of

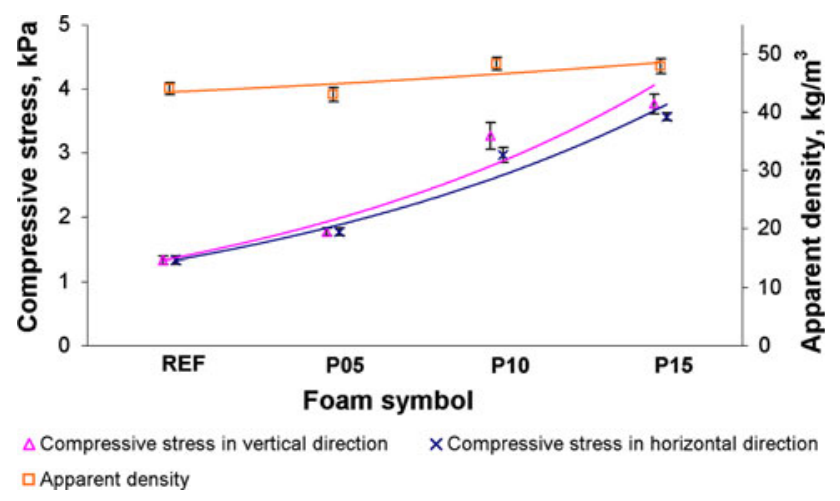

Fig. 2 Effect of palm oil polyol concentration (5, 10, and $15 \mathrm{wt} \%$ in polyol premix) on apparent density and compressive stress of flexible polyurethane foams reference material (Fig. 2). The changes of apparent density are ambiguous, however an increase is observed as the effect of petrochemical polyol replacing with palm oil polyol. Probably, it can be related to nearly 7 times higher viscosity of palm oil polyol, than of replaced petrochemical polyol G1000.

The investigated foams slightly differed in apparent density, therefore their mechanical properties could be directly compared. It was found that the increase of palm oil polyol content in the formulation causes higher compressive stress values of the modified foams. The compressive stress values (measured in both directions, parallel and perpendicular to the foam rise) of the foams modified with palm oil polyol were higher than that of the reference foam. The content increase of palm oil polyol up to $15 \mathrm{wt} \%$ in the polyol premix caused the higher (almost three times) the compressive stress at $40 \%$ in comparison to reference foam (Fig. 2).

Interesting results were obtained in the case of the measurement of tensile strength and elongation at break of investigated foams (Fig. 3). The replacement of petrochemical polyol with palm oil polyol significantly affected tensile strength of modified foams. Although the functionality of the petrochemical polyol is higher (3.0) than that number average functionality of hydroxyl groups of palm oil polyol (2.5), all the modified foams (P05, P10, P15) have higher tensile strength (respectively 60.0, 80.3 and $86.3 \mathrm{kPa}$ ). In the case of the foam modified with $15 \mathrm{wt} \%$ of palm oil polyol tensile strength is nearly twice higher compared to reference foam $(47.6 \mathrm{kPa})$. These changes are also the effect of hydroxyl groups position in the palm oil polyol molecule. Petrochemical polyol G1000 is polyether triol with hydroxyls at the ends of polymeric chains, while palm oil polyol has the hydroxyls in the middle of the fatty acid chains. Both polyols have the same molecular weight and therefore after reaction with isocyanate, compared polyurethane structures contain the soft

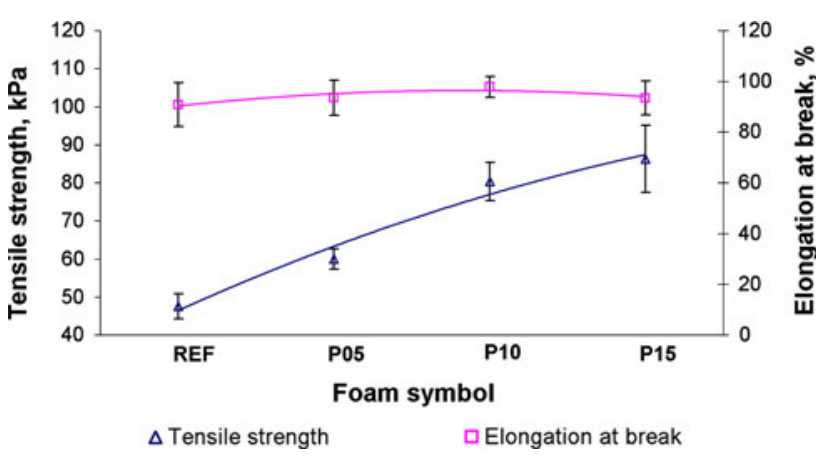

Fig. 3 Effect of palm oil polyol concentration (5, 10, and $15 \mathrm{wt} \%$ in polyol premix) on the tensile strength and elongation at break of flexible polyurethane foams 
segments with different length (shorter in the case of palm oil based polyol) between branching points. These shorter soft segments of PUR matrix in the case of the foams with palm oil polyol have more beneficial influence on mechanical properties of final products than the effect of cross-linking density caused by higher functionality of the petrochemical polyol G1000. In the case of the modified foams, the increase of elongation at break values was also observed, however differences in relation to the reference material are negligible. The most beneficial increase of this property was observed for foam P10 (97.8\%) in comparison to reference foam $(90.8 \%)$.

The resilience is extremely important in the case of the specific type of flexible foams, so called viscoelastic foams, that characterized by higher energy absorption. The resilience is affected by the morphology of foam, specifically by the ratio between soft and hard segments. The ratio of soft and hard segments, their distribution and separation in the polyurethane matrix significantly affects viscoelastic properties of final products [25]. These characteristics are reflected in the $\tan \delta$ values and ball rebound results [26].

In our investigation the similar trends in the changes of cell structure (including anisotropy and closed cell content) and ball rebound test results were observed as the effect of palm oil polyol content in the polyurethane systems. The resilience of modified foams increased from 11.3 to $13.8 \%$

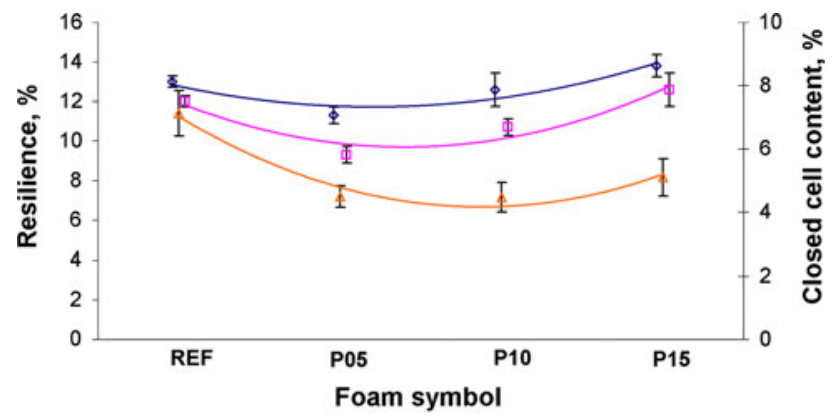

○ Resilience in vertical direction $\square$ Resilience in horizontal direction $\triangle$ Closed cell content

Fig. 4 Effect of palm oil polyol concentration (5, 10, and $15 \mathrm{wt} \%$ in polyol premix) on the resilience of flexible polyurethane foams and closed cell content (measured in vertical direction) and from 9.3 to $12.6 \%$ (measured in horizontal direction) with increasing content of palm oil polyol while the resilience of the reference foam was respectively 13.0 and $12.0 \%$ (Fig. 4). Probably, dangling fatty acid chains have plasticizing effect and made the modified foams more viscoelastic, what was reflected by slightly decrease of the resilience values in ball rebound test of the foam $\mathrm{P} 05$. In the case of the foams with higher content of palm oil polyol in PUR formulations (P10, P15) the increase of resilience was observed. It may be explained as the results of higher closed cell content in these foams, what allows the foams for faster response due to the compressed air closed in such cells (Fig. 4).

The properties of foams considerably depend on the raw materials, especially polyols which are used in PUR formulations. Various chemical groups such as urethane, urea,

Table 3 Temperatures $\left({ }^{\circ} \mathrm{C}\right)$ at which weight loss reached the specified levels

\begin{tabular}{llllll}
\hline Sample & $\mathrm{T}_{2 \%}\left({ }^{\circ} \mathrm{C}\right)$ & $\mathrm{T}_{5 \%}\left({ }^{\circ} \mathrm{C}\right)$ & $\mathrm{T}_{10 \%}\left({ }^{\circ} \mathrm{C}\right)$ & $\mathrm{T}_{20 \%}\left({ }^{\circ} \mathrm{C}\right)$ & $\mathrm{T}_{50 \%}\left({ }^{\circ} \mathrm{C}\right)$ \\
\hline REF & 234 & 254 & 269 & 287 & 330 \\
P05 & 230 & 249 & 266 & 287 & 336 \\
P10 & 223 & 248 & 266 & 290 & 343 \\
P15 & 223 & 248 & 266 & 291 & 349 \\
\hline
\end{tabular}

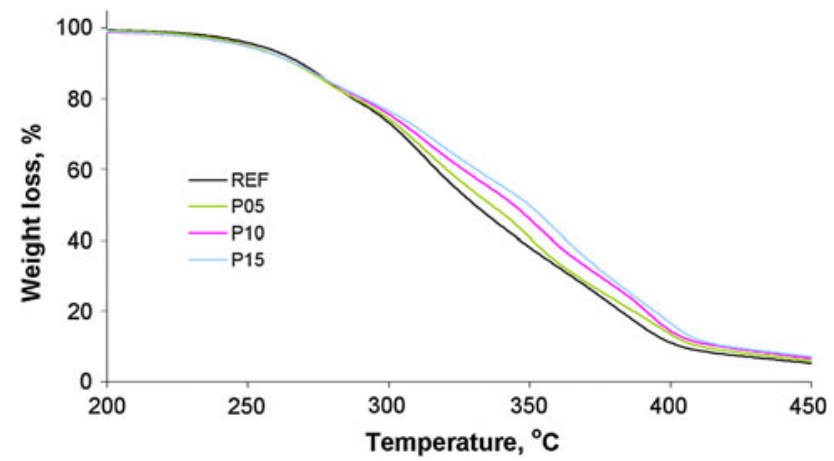

Fig. 6 Set of thermograms of reference polyurethane foam (REF) and foams modified by 5,10 , and $15 \mathrm{wt} \%$ of palm oil polyol (P5, P10, and P15) in polyol premix
Fig. 5 Thermograms of reference (a) and modified P15 (b) foams
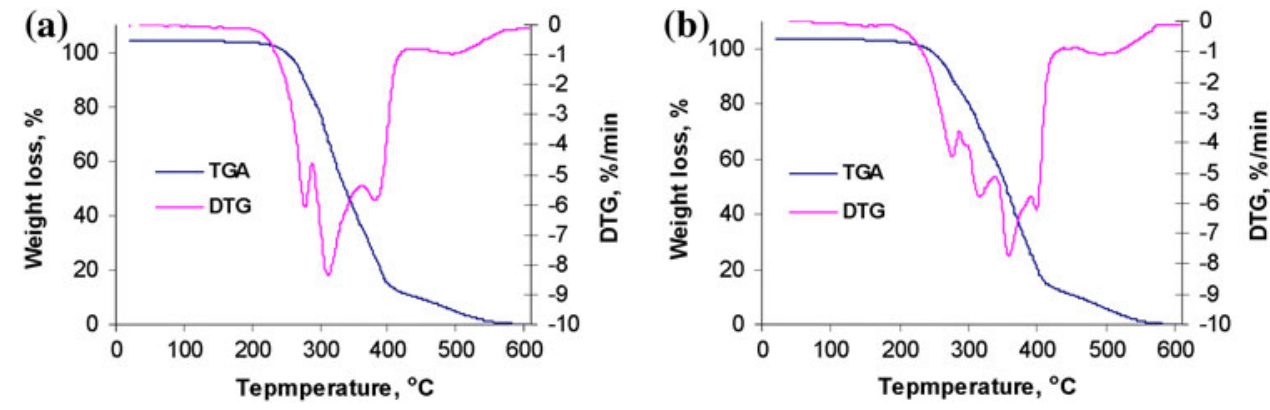


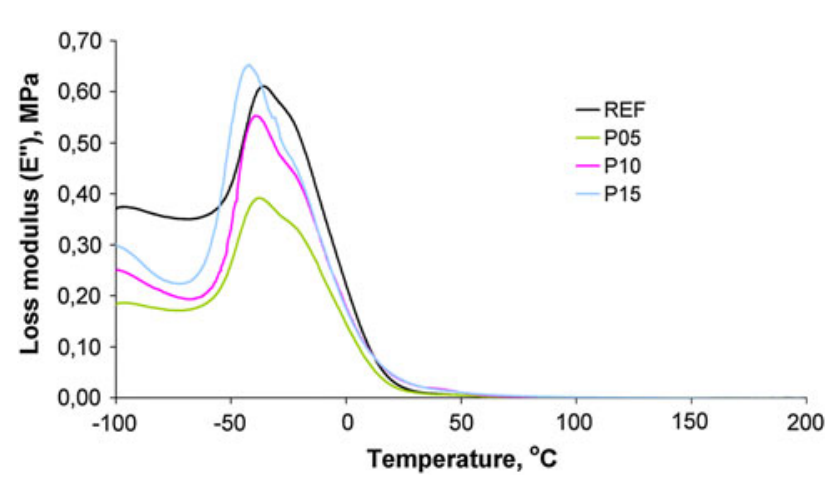

Fig. 7 Set of loss modulus (E") of reference and modified polyurethane foams

allophanate and others, are identified in PUR materials. The range of thermal decomposition of PUR foams is strongly influenced by the physical characteristics of the polyurethane matrix, mainly, internal crosslinking, hydrogen bonds and the inner crystalline structure [27]. The thermal decomposition of polyurethane matrix occurs in the random places by one or more of the following three mechanisms: depolymerisation (dissociation to the isocyanate and polyol precursors), dissociation (to a primary amine, an olefin and $\mathrm{CO}_{2}$ ) and elimination of $\mathrm{CO}_{2}$ leading to the replacement of the urethane bond by secondary amine groups [28].

In Fig. 5, TGA and DTG curves of thermal decomposition of reference (Fig. 5a) and modified P15 (Fig. 5b) foams under air atmosphere are shown. The DTG plots are characterized by a multi-stage decomposition process. Three steps decomposition of reference foam started at ca. $234{ }^{\circ} \mathrm{C}$. In the case of the foams modified with palm oil polyol (samples P05, P10, P15), the start of decomposition at the slightly lower temperature was observed (ca. $223-230{ }^{\circ} \mathrm{C}$ ) and proceeded in four steps. At ca. $560{ }^{\circ} \mathrm{C}$, decomposition can be considered as being completed. Detailed TG data of the decomposition are summarized in Table 3.

Analysis of DTG curve indicates the first maximum at $277-278{ }^{\circ} \mathrm{C}$ for all samples. It corresponds to the decomposition of urethane bonds [29]. The maximum rate of weight loss at $300-409^{\circ} \mathrm{C}$ represents the decomposition of (a)

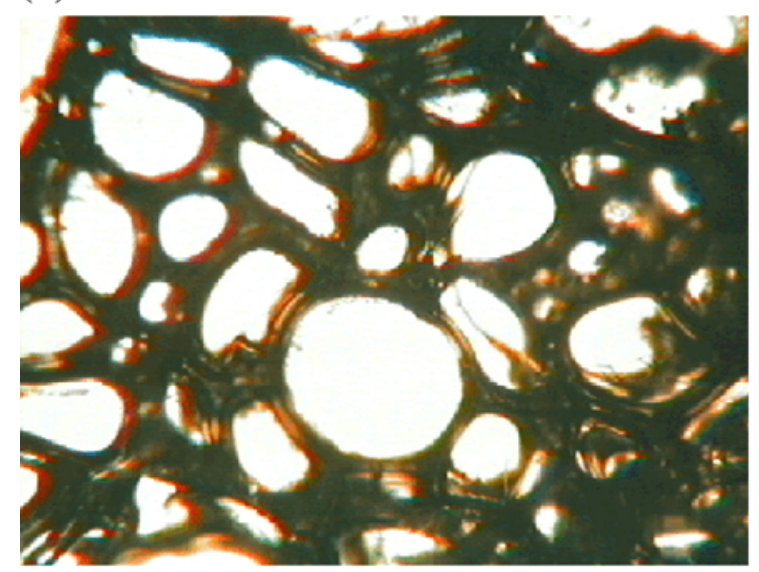

(c)

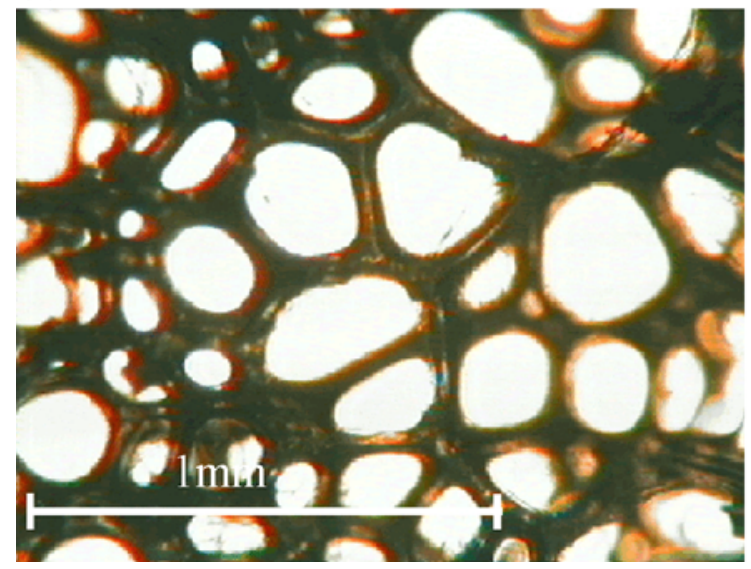

(b)

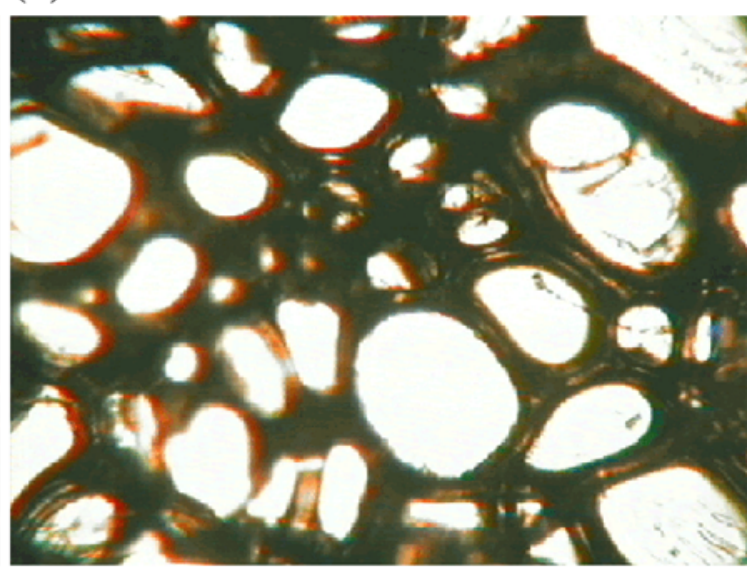

(d)

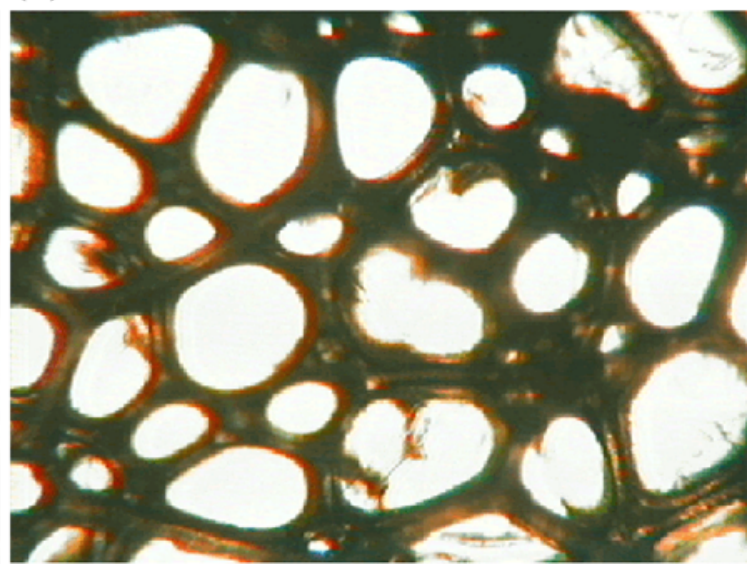

Fig. 8 Cellular structure of polyurethane foams: a REF (reference foam), b P05, c P10, d P15 (foams modified with 5, 10 and 15 wt\% of palm oil polyol in polyol premix) 
Table 4 Selected parameters of the cellular structure of flexible polyurethane foams

\begin{tabular}{lllll}
\hline \multirow{2}{*}{$\begin{array}{l}\text { Average values of parameters } \\
\text { of the cells }\end{array}$} & \multicolumn{5}{l}{ Foam symbol } \\
\cline { 2 - 5 } & REF & P05 & P10 & P15 \\
\hline Cell cross-section surface, $\mathrm{mm}^{2}$ & 0.0145 & 0.0141 & 0.0132 & 0.0131 \\
Cell height, mm & 0.1209 & 0.1182 & 0.1094 & 0.1097 \\
Cell width, mm & 0.1142 & 0.1126 & 0.0997 & 0.1018 \\
Anisotropy index & 1.0590 & 1.0490 & 1.0970 & 1.0780
\end{tabular}

the polyol backbone. In the case of sample P05, P10 and P15 the additional stage of the decomposition with maximum at ca. $350-359{ }^{\circ} \mathrm{C}$ is presented. Moreover, the set of thermograms shown in Fig. 6 indicates a decrease in the rate of weight loss with the increase of palm oil polyol content in foam formulations.

Dynamic mechanical analysis (DMA) was used to measure glass transition temperature $\left(\mathrm{T}_{\mathrm{g}}\right)$ of PUR matrix of prepared foams (Fig. 7). In the case of foams modified with palm oil polyol, this parameter has tendency to be lower as the effect of higher content of palm oil polyol in PUR foam. $\mathrm{T}_{\mathrm{g}}$ value of foam samples decreased from $-35{ }^{\circ} \mathrm{C}$ (for reference foam) to $-42{ }^{\circ} \mathrm{C}$ (for foam P15). It may be the result of plasticization effects of dangling chains of fatty acids.

Favorable effects of palm oil polyol in flexible polyurethane foams were also noticed in their cellular structure. It is clearly visible in Fig. 8 (the modified foams and reference materials are compared) that the increase of palm oil polyol in PUR formulation gives more regular cell structure.

The results of image analysis of the cellular structure of foams are shown in Table 4. The increase of palm oil polyol content allowed to create the cells with more uniform size. This is due to the presence of palm oil polyol, that acts as an additional surfactant. However, this more beneficial cell structure may be also the effect of higher viscosity of palm oil polyol in comparison to viscosity of petrochemical polyol G1000.

\section{Conclusions}

The presented results confirmed that polyol synthesized using palm oil can be successfully applied for modification of flexible polyurethane foams. The modifications of polyurethane formulations with palm oil polyol allowed improvement of selected properties of flexible polyurethane foams.

The replacement of petrochemical polyol with palm oil polyol up to $15 \mathrm{wt} \%$ in the polyol premix resulted in more uniform cell size, increased apparent density and considerable improvement of compressive stress. Increase of the content of palm oil polyol strongly affects on the tensile strength of the flexible polyurethane foams. In the case of the foam modified with $15 \mathrm{wt} \%$ of palm oil polyol, the considerable increase (even $80 \%$ ) of tensile strength is possible in comparison to the reference foam, while the value of elongation at break may be kept on similar level.

The foams modified with palm oil polyol up to $15 \mathrm{wt} \%$ only slightly change the ability of energy absorption. The resilience increases from $11.3 \%$ for reference foam to $13.8 \%$ for the foams modified with $15 \mathrm{wt} \%$ of palm oil polyol. The modification of polyurethane systems using palm oil polyol also slightly decreases the $\mathrm{Tg}$ value of the foams from $-35{ }^{\circ} \mathrm{C}$ for reference foam to $-42{ }^{\circ} \mathrm{C}$ for the foam modified with $15 \mathrm{wt} \%$ of palm oil polyol.

The presence of palm oil-based polyol in the foam structure allows to decrease the rate of weight loss during the thermal decomposition.

Acknowledgments Research were co-financed from means of European Regional Developed Fund and from means of State Budget as a part of Operational Programme Innovative Economy for 2007-2013 Contract no UDA-OP-IE.01.03.01-00-092/08-00, Annexe to the contract no UDA-OP IE.01.03.01-00-092/08-01 from 15 September, 2009, Annexe no UDA-OP IE.01.03.01-00-092/08-02 from 26 April, 2010 "New eco-friendly polymer composites with renewable sources" realized as a part of Measure 1.3 OP IE, Sub-measure 1.3.1.

Open Access This article is distributed under the terms of the Creative Commons Attribution Noncommercial License which permits any noncommercial use, distribution, and reproduction in any medium, provided the original author(s) and source are credited.

\section{References}

1. Randall D, Lee S (eds) (2002) The polyurethanes book. Wiley Ltd, New York

2. Schaefer BF (2005) Science 308:1267

3. Shogren RL, Petrović ZS, Liu Z, Erhan SZ (2004) J Polym Environ 12:173

4. Helling RK, Russell DA (2009) Green Chem 11:380

5. Guo A, Javni I, Petrović ZS (2000) J Appl Polym Sci 77:467

6. Prociak A (2008) Polimery 53:195

7. Petrović ZS, Yang L, Zlatanić A, Zhang W, Javni I (2007) J Appl Polym Sci 105:2717

8. Petrović ZS (2008) Polym Rev 48:109

9. Seniha Güner F, Yagci Y, Tuncer Erciyes A (2006) Prog Polym Sci 31:633

10. Wasilewicz-Niedbalska W, Chmielarz B, Kosmacińska B, Dyczewski M, Gwardiak H, Wiślicki B, Zdrodowska B (2001) Przemysł Chemiczny 80: 154

11. Petrović ZS, Zhang W, Javni I (2005) Biomacromolecules 6:713

12. Petrović ZS, Zlatanić A, Lava CC, Sinadinović-Fiser S (2002) Eur J Lipid Sci Technol 104: 293

13. Guo A, Demydov D, Zhang W, Petrović ZS (2002) J Polym Environ 10:49

14. Schuchardt U, Sercheli R, Vargas RM (1998) J Brazil Chem Soc 9: 199 
15. Hill K (2000) Pure Appl Chem 72:1255

16. Pawlik H, Prociak A, Pielichowski J (2009) Czasopismo Techniczne 1-Ch:111

17. Tanaka R, Hirose S, Hatakeyama H (2008) Bioresour Technol 99:3810

18. U.S. Department of Agriculture (March 2011) Monthly vegetable oils production and prices

19. Lee CS, Ooi TL, Chuah CH, Ahmad S (2007) J Am Oil Chem Soc 84:1161

20. Badri KH, Othman Z, Ahmad SH (2004) J Mater Sci 39:5541

21. Shaari NZK, Lye OT, Ahmad S (2006) JOPR 18:198

22. Shaari NZK, Lye OT, Ahmad S (2004) J Oil Palm Res 16:66

23. Patent US 2008293913 A1
24. Zlatanic A, Lava Ch, Zhang W, Petrovic ZS (2004) J Polym Sci Part B 42:809

25. Zhang Q, Yu J (2005) "High performance all MDI viscoelastic foams" technical conference and trade fair. Polyurethanes, Houston, U.S.A

26. Vaughan BR, Wilkes GL, Dounis DV, McLaughlin C (2011) J Appl Polym Sci 119:2698

27. Pielichowski K, Kulesza K, Pearce EM (2003) J Appl Polym Sci 88:2319

28. Ravey M, Pearce EM (1997) J Appl Polym Sci 63:47

29. Molero C, de Lucas A, Rodriguez JF (2008) Polym Degrad Stab 93:353 